\title{
Ellipsis
}

Volume 44

Article 26

2017

\section{Mission Dolores}

Chelsey Shannon

Follow this and additional works at: https://scholarworks.uno.edu/ellipsis

\section{Recommended Citation}

Shannon, Chelsey (2017) "Mission Dolores," Ellipsis: Vol. 44 , Article 26.

DOI: https://doi.org/10.46428/ejail.44.26

Available at: https://scholarworks.uno.edu/ellipsis/vol44/iss1/26

This Literary Criticism is brought to you for free and open access by the Department of English and Foreign Languages at ScholarWorks@UNO. It has been accepted for inclusion in Ellipsis by an authorized editor of ScholarWorks@UNO.For more information, please contact scholarworks@uno.edu. 


\title{
Mission Dolores
}

Chelsey Shannon

\section{The Malcolm Magaw Prize for Best Graduate Student Essay}

\author{
"Some people had told him that, after all, American girls were exceedingly innocent; \\ and others had told him that, after all, they were not." \\ - Henry James, Daisy Miller: A Study
}

Her name is Dolores. She was born in a novel by Vladimir Nabokov over forty years before the Centers for Disease Control and Prevention launched the Adverse Childhood Experiences (ACE) Study, a large-scale investigation of the effects of childhood trauma on later development ("About the CDC-Kaiser ACE Study"). The categories of traumas studied are universal: neglect (emotional, physical); addiction of a caregiver; death or other permanent removal of parent(s); and abuse (emotional, physical, sexual). From this study emerged the ACE score, which indexes an individual's traumatic experiences on a scale of zero to ten, with each number over three correlating with exponential potential for negative outcomes in later life. These include proneness to substance abuse, depression, intimate partner violence, unintended or adolescent pregnancy, early initiation of sexual activity, and suicidality. My number is five; Dolores's would be nine.

But Dolores's number doesn't define her any more than mine defines me; it is not what we know her by. We know her by her saddle shoes, her heart-shaped sunglasses, the iconic accessory which she was, in fact, never noted to have worn by her most "conscientious recorder" Humbert Humbert - and were there anything to note, he would have (Nabokov 72). For when it comes to Dolores's physicality, Humbert never misses a beat, "would turn [his] Lolita inside out and apply voracious lips to her young matrix, her unknown heart, her nacreous liver, the sea-grapes of her lungs, her comely twin kidneys" if he could (165). In this sense, he is like Nature, who, he muses, is "stunned by the sights she sees"sights such as a man, somewhere around his forties, shuttling a girl, of twelve, thirteen, then fourteen, across America's yearning and open lowlands, from ocean to ocean and back again, man stealing girl away to a hidden path in the Colorado Rockies for a quick, al fresco fuck - man conquering child upwards of three times a day (221). Is this Nature?

Yes, groans Humbert Humbert. This is Nature at her most monstrous and her most transcendent.

And it is through the monster that we know the child, called hardly ever "Dolores" - too sad - but turned "Lolita," light of monster's life, fire of monster's loins, his "russet Venus," his "not-quite-nubile" concubine (9, 270, 230).

I first read Lolita at sixteen (well outside the realm of nymphancy, though I'd never fit Humbert's expertly honed criteria, anyway). Beneath an atmosphere of eroticism so heady it misled prospective publishers to expect a pornographic novel, the book's first part details the wild hand Fate deals "Humbert Humbert," the ambiguously European academic who winds up the widowed stepfather of 
Dolores, the child with whom he's grown sexually obsessed (313). His possession of her situates largely on the American roadways, by which he freights his prize along a rambling bacchanal of themed motels, would-be single rooms, and the duplicitous surreality of once-dream turned waking nightmare. Part two unfolds Humbert's inevitable turn with Nemesis: despite his best efforts to keep Dolores off the radar of friends and authorities alike, she eventually manages to loosen herself from his clutches.

Seduced as I was by Humbert's baroque, fiercely Gordian turns of phrase, there was hardly room for me to feel anything about Dolores - further, there is hardly room for Dolores in the text: Dolores, pseudo-surnamed "Haze," painted by Humbert in fuzzy browns and fathomless grays, she, his blurred beauty, her fresh lipstick the only thing vivid about her. Is Dolores dull or cunning? preternatural or prosaic? Neither, both, depends on the day, Humbert Humbert is not sure; it depends on how Humbert is feeling about Humbert. Today, is he a monster, an Enchanted Hunter preying on his tenaciously tracked nymphet? Or is he, today, the victim of Nature, and of Lolita's charms, a beast piteously burdened?

Though they are as errant as the heart which fails him before he can be tried for his crimes, we have only Humbert Humbert's recollections to go by; the novel is framed as a manuscript he composes from prison, where he awaits sentence not for his villainy against Dolores, but for murdering the man who helped her escape Humbert's custody. So, absurdly, in a book named for some version of her, Dolores herself hangs around Humbert's words like "the small ghost of somebody [he] had just killed," her actions and motivations wonkily matured when her captor needs her to seem less his victim, and re-infantilized when her growing agency threatens him (140). Perhaps, for Humbert, that ghost is Dolores, leaving behind only the entity which he calls Lolita. How appropriate that he only glimpses her expression of utter helplessness by chance in a refracted mirror image, hears her nightly sobs only through his own feigned sleep (283, 176). "I would like to describe her face, her ways - and I cannot," Humbert admits, "because my own desire for her blinds me when she is near" (44).

As a teenaged reader, I was entranced by Humbert's telling, right down to his climactic declaration of undying devotion to "[his] Lolita, this Lolita," one "big with another's child" and, for all intents and purposes, an adult (278). My subsequent cogitations about the novel sought to digest this apparent complication of his child-centric desire, always centering the substance of Humbert's feelings. Despite my fellowship with Dolores as an American girl, a once-abused girl, a possessor of a high ACE score, I went along with her relegation to the scant negative space of such an impeccably crafted novel without question.

Now, I find my docile acceptance of Dolores's absence a much more dogged haunter than Humbert's supposedly puzzling profession of "love."

$$
* * *
$$

The ability of Humbert Humbert's language to make us overlook, even for an instant, the hideous reality he forced on his young victim would be a bold if 
chilling example of the power of literature, and nothing more, if the reader's amnesia did not extend beyond the closed circuit of the novel. But it does, suffusing into the vaporous realm of popular culture, wherein the name 'Lolita' is applied seemingly without remembrance of its flipside, 'Dolores,' thus reducing a kaleidoscopically rich character to "a general reference to girls considered sexually precocious" - or, as Urban Dictionary puts it, "a term used to describe a prepubescent or adolescent girl who is attractive and sexually responsive" ("Lolita (term)"; "lolita"). The Lolita persona, as it exists in both pornography and pop culture, has accrued such intrigue as to all but blot out Dolores, its necessary counterweight, in the cultural imagination. The Lolita references of Lana Del Rey's 2012 album Born to Die, to name one example, reproduce a certain submissive yet seductive sexuality, in which the speaker plays up her childishness to the older men she hopes to attract. One of the album's tracks, which shares the name of the novel and the figure, poses 'Lolita' as a moniker of carefree coquetry: "Kiss me in the P-A-R-K park tonight / P-A-R-K, let them all say / Hey, Lolita, hey / Hey, Lolita, hey / I know what the boys want, I'm not gonna play" (Lana Del Rey). In such contexts, the figment of Lolita is fulfilled in a way that Dolores Haze, being a character who is child and not a persona, never could have matched. Indeed, only when the child is removed from the equation can any iteration of the sovereign, inexorable Lolita - the chimera which Humbert attempts, through his abuse and crimes, to cudgel into existence-appear.

However, the self-consciously provocative imagery of Born to Die is not entirely alien to the pages of Lolita. One scene finds Humbert furtively watching the show Dolores puts on for Clare Quilty, the playwright turned pornographer who will eventually spirit her away. Dolores entertains Quilty's terrier with a bright-eyed, cheesecakey delight, intentionally missing the dog's ball and falling "on her back, with her obscene young legs madly pedaling in the air; I could sense the musk of her excitement from where I stood"-an act for which Humbert deems her a "vile and beloved slut" (Nabokov 237). And this is part of Dolores, part of what she does: comprehend the value of the fantasies sutured to her young body, and her own ability, indeed her imperative, to barter with them.

$$
* * *
$$

While it would be comforting to dismiss Dolores's sexuality as existing only in the eyes of certain beholders, doing so further disempowers an already woefully mistreated character. In the words of Sally Mann, whose occasionally nude photographs of her young children generated controversy in the early nineties:

The image of the child is especially subject to that kind of perceptual dislocation; children are not just the innocents that we expect them to be. They are also wise, angry, jaded, skeptical, mean, manipulative, brooding and devilishly deceitful...But in a culture so deeply invested in a cult of childhood innocence, we are understandably reluctant to 
acknowledge these discordant aspects or, as I found out, even fictionalized depictions of them. (Mann)

Likewise, Dolores mustn't be simplistically situated, can't be left as either the pseudo-innocent siren perpetuated by Lana Del Rey and others, or the asexual child, made sexual only through Humbert Humbert's pedophiliac gaze - the truth, the Haze between, is far more complicated.

It is entirely and irrevocably beyond doubt that Dolores was Humbert's victim. It is entirely and irrevocably beyond doubt that Humbert was Dolores's abuser, kidnapper, and rapist. Between the two there was no hope of consent or, in firm defiance of the Vanity Fair endorsement featured on the 1997 Vintage International edition of the novel's cover, of any "convincing love story." But should these absolute truths also negate Dolores's sexual agency? Would her story have been more tragic had she not, as Humbert is eager to point out, had a "lover" before himself? When Humbert attempts to figure Charlie, the thirteenyear-old with whom Dolores first has intercourse, as her true rapist, he reflects a common misconstruction of Dolores, and of young sexuality in general (Nabokov 150). For the central tragedy of Dolores is not, precisely, sexual purity being destroyed by male predation, but of a burgeoning sexuality being distorted by the hands of an abuser.

Even apart from such sexual performances as the display for Quilty, young Dolores was not asexual, and needn't have been: in the days before her mobile imprisonment by Humbert, she is active and unshy with her desire, whether for (initially) Humbert, or for Charlie, or Elizabeth Talbot, a classmate with whom she makes her first erotic explorations. These latter connections, respectively aggrandized by Humbert to lovership and dismissed by him as "sapphic diversions," are consensual, non-traumatic, and developmentally healthy; they predate Humbert's abuse of Dolores, and so originate from her intrinsic erotic appetite (136). While precocious, Dolores's full embrace of her desire is remarkably forthright and, in the sense of children asserting autonomy over their bodies and selves, radical.

Ideally, Dolores would have been given appropriate boundaries within which her desire could safely flourish, guidance that would have validated the existence of her wanting, and helped her channel it in manners both selfexpressive and -protective. But sadly, certainly, Humbert Humbert is no parent but predator, seeing not young woman Dolores, but nymphet Lolita, figmental fulfillment of his own erotic trajectory, existing solely to torture, or be possessed by, him. It is at this point - the point of Humbert, the adult in the first of their many shared hotel rooms, "playing" along with Dolores's advances instead of curbing them swiftly - that Humbert "breaks her life," as he much later knows he has done (279). Where sexuality might have been set up as a site of clarity, abundance, and self-possession for Dolores, it instead becomes one of chaos, travesty, and abuse. 
But this, here, is not about Humbert Humbert. Outside of Lolita's pages, a reader is allowed to examine the story without its narrator's claw-like hand guiding their neck. In his essay "On a Book Entitled Lolita," Nabokov describes the "first little throb," mysterious even to himself, that eventually led to the crown jewel of his oeuvre: "a newspaper story about an ape in the Jardin des Plantes, who, after months of coaxing by a scientist, produced the first drawing ever charcoaled by an animal: this sketch showed the bars of the poor creature's cage" (311). In terms of Lolita, the beholder of the figurative bars is open to interpretation. Is it Humbert (as he would have it), trapped within his pathological desire? Dolores, trapped extrinsically within the same? Nabokov himself, constricted as he was by ideas of morality and convention, when he set out to find his Lolita a publisher? Or is it Lolita's reader, locked in by Humbert's sleight of language, unable to see clearly the locus of all the novel's fuss?

So, let's look at Dolores herself: a white American girl coming of age in the glossy post-war period, a time of the status quo asserting itself with an applecheeked vengeance. Middle-class white women were re-relegated to the home. Dior stepped in to revive the ornament and frill of women's fashion. Popular beauty standards ebbed from the angular silhouette of Katharine Hepburn to make way for Jayne Mansfield and Marilyn Monroe, whose voluptuous bodies became fresh emblems of the sexual difference downplayed during the war years. Celebrated soldiers, returned from overseas, were encouraged to forget the traumas of battle and find contentment in family life - the "back home" they'd been fighting for all along. Now that the war was over, so the story went, everyone just wanted things to go back to the way they'd once been.

Though this period of time was home to more counterculture and dissent than its image typically conjures, Dolores, for one, is quite content with conventionality. At one point Humbert opines that "there is nothing more conservative than a child" - and to be sure, Dolores stays well within the margins of bourgeois expectation: she is a gum-chewing, virile consumerist, poring over gossip magazines and comic books, memorizing the words to the teenage love ballads dominating the AM airwaves (186). At the movies she favors musicals, westerns, and underworld detective thrillers, each their own cross-section of mythical Americana - and, for all the trauma of her young life, will often appear "glad as an ad," for "she it was to whom ads were dedicated" $(170,148,161)$.

And while, in childhood and adolescence, Dolores was cruelly denied the convention she craved, in the brief glimpse of adult life that Nabokov allows her (and the reader), she cultivates it almost blithely, marrying a young, blue-collar veteran named Dick, toward whom she is womanly and wifely, a happy haverand-holder of his grease-stained hands. She wears rhinestone glasses and chainsmokes cigarettes. Dick and Dolores have a dog and Dolores carries Dick's child.

Taking place in her seventeenth year, Dolores's pregnancy could be read as a negative outcome of her ACE score, even though it is preceded by holy wedlock. But, given Dolores's demonstrably pragmatic teleology, perhaps she figures her pregnancy more as a sanctioned manifestation of her brutally mishandled sexuality. When Humbert tracks down the adult Dolores, who had written and asked him for money, she is disarmingly blasé. At first evading 
Humbert's questions about her "betrayal" of him two years earlier (that is, her using the drastic means at her disposal to escape his violence) with breezy rebuffs, she eventually answers them with an even factuality: it was all so long ago, after all, and this was her life now, and would Humbert please fork over the cash and be on his merry way (275)?

Doubtless the trauma of Dolores's youth hadn't the chance, at seventeen, to be fully processed. But beyond her dowdy attire, her cordial insouciance (she even calls Humbert, in his most pathetic moment, "honey"), and her less than glamorous new life, there radiates a resilience that is, unfortunately, eclipsed by the volume of Humbert's grisly despair - both within the novel and in popular understanding thereof (279). As much as Humbert mocks her mechanic husband and the closeness of the quarters he is able to provide, Dolores - not "his Lolita" at all - has managed, against staggering odds, to create a perfectly typical life for herself. It is the unlikely fulfillment of her every wish as a girl, those achingly predictable wishes once juxtaposed with the monstrous abnormality of her circumstances.

In 2006, a thinktank called Southern Kennebec Healthy Start designed a questionnaire that gauges such resilience (Stevens). The resilience score, which can serve as a complement to the ACE score, corresponds to the number of developmentally protective factors present in one's youth. In the case of Dolores, some questions concerning early childhood conditions are unanswerable (did she feel her mother and father loved her when she was very young? was she played with as an infant?). But it is certain that she lacked other factors in her later childhood and early adolescence, such as constructive interest from teachers and neighbors (even when Dolores and Humbert are settled in the town of Beardsley, he keeps her strictly isolated from the community); the presence of a trustworthy confidante (Clare Quilty, the only adult who knows Dolores's story, frees her from Humbert only to abandon her when she refuses to appear in his films); and the enforcement of reasonable rules in one's home (in the simulacrum of family life which Humbert provides Dolores, the only certain rule is daily rape).

The dearth of protective factors in Dolores's youth, coupled with her high ACE score, make all the more phenomenal her ability to cultivate a sense of normalcy, however modest, in adulthood. Yet this unassuming life, cut short by her death in childbirth, is only the dénouement of Dolores's mental and emotional resistance, which, when not patronized or taken as offensive by Humbert, is conveyed with a conspicuous lack of verbosity on his part. These are the sorts of things he deems "unprintable," worthy only of summary and not the ranging illustration he grants himself: Dolores's declaring recollection of first being molested by Humbert in her mother's home - thus shattering Humbert's delusion of these early fondlings eluding his existentially seductive Lolita. Or Dolores accusing Humbert of killing her mother, which, given Humbert's eventually actualized murderous inclinations, in a sense might as well be true (Nabokov 61, 205).

Amplification of such sites of resistance is critical to a comprehensive reading of Dolores's character. More complicatedly, it's this same sense of intrinsic resistance which fuels Dolores's initial overtures toward Humbert 
Humbert - for it is she who kisses him first (66). Dolores does not do these things because she is a "sexy" child. Dolores does these things because she has desire, and the will to enact her desires, that will indeed most indefatigable in childhood - even when, as in Dolores's case, it is threatened with obliteration.

To be clear: As a child, Dolores is not responsible for the sorry recourses she is able to devise, such as demanding compensation from her chronic rapist, or fleeing said rapist with a child pornographer. Nor, as a child, is she responsible for adults' interpretations of and responses to her desire, desire that has an inviolable right to exist. The inability of Dolores to exist as Dolores-not angel, not devil, but forsaken, human child - reflects a broader discomfort with child sexuality: either it doesn't exist at all, or it exists only in exploitative contexts, a false binary that permeates American culture. This same culture had no trouble ignoring a presidential candidate's indictment for raping a thirteen-year-old —or going on, as it happened, to elect this candidate, and gawk impassively as the victim was bullied into dropping her charges within the same week (Yuhas).

A society that flattens its understanding of children, especially girls, is one that does not respect or protect them. Or, therefore, itself.

$$
* * *
$$

In 1977, a petition circulated in France championing the decriminalization of sexual contact between adults and minors under fifteen. Philosopher Michel Foucault, one defender, maintained that such rigid legalization of what does and does not constitute acceptable contact between two subjects effectively robs child subjects of the ability to articulate their own experiences, and thus of their right to be heard: "[T]o assume that a child is incapable of explaining what happened and was incapable of giving [her or] his consent are two abuses that are intolerable, quite unacceptable... The child may be trusted to say whether or not [(s)]he was subjected to violence" (Foucault 283).

No doubt such an argument functions best in some ideal reality where children could not be subjected to the psychological and physical manipulation known as grooming, through which the adult predator gradually acclimates the child target to the eventuality of sexual contact. It's a process that Humbert Humbert shepherds Dolores seamlessly through, as when he explains that "a minor female, who allows a person over twenty-one to know her carnally, involves her victim into statutory rape," and other such sly perversions of their situation (Nabokov 150).

But one need not agree with Foucault's radical position to find salient his central argument, one which discredits facile readings of both Dolores and Lolita. In colluding in a mainstream understanding of 'Lolita' as a sexually precocious female child, all titillated subtext attendant, are we not deeming Dolores incapable of explaining the violence perpetrated against her? Are we not ignoring her plain articulations of "incest," of "rape" $(119,141)$ ? Similarly, in allowing ourselves to be seduced by the beauty of Humbert's (and Nabokov's) language, to the exclusion of a deep recognition of Dolores's power, are we not complicit in an erasure of that power? 
"Imagine me," Humbert implores, "I shall not exist if you do not imagine me" - an ironic plea, in that any reader of Humbert's text, drunk on his florid language as they become, has little choice but to imagine the teller of the tale (129). Yet his solipsism is characteristic, and contagious. Indeed, both of the manuscript titles suggested by Humbert (included in a forward by the work's fictional editor) manage to elide Dolores: "Lolita," he calls it, "or the Confession of a White Widowed Male" (3). In his entire framing of his experiences, Humbert is unable to acknowledge the rightful recipient of the reification he solicits for himself: Dolores, hardly ever called by her proper name, who has suffered being misheard and mis-imagined since she was introduced to the collective psyche.

$* * *$

In wandering the American West, the man and the girl tour a certain Mission Dolores, upon which Humbert Humbert parenthetically remarks: "good title for book" - that is, his account of the ordeal to which he subjected Dolores Haze (158). But of course, Humbert, like many in his audience, was never interested in Dolores proper, but in his own feverish construction of 'Lolita.' And so the project implied in the name he, outrageously, considers for his own depraved rehashings falls, imperatively, to readers of this story, of this culture, of female and child characters as a whole.

As if to foreclose certain avenues of analysis, Nabokov asserted that Lolita "has no moral in tow" (314). Yet, in positive dissent, I propose a reexamination of the work's pivotal, rather than titular, character, the "delicate beauty ever present in the margin of our undeserving journey"- - here again Humbert's words, the "our" meaning his and Lolita's (152). But the journey he so piously deprecates was never Dolores's, only Humbert's, along with the readers he buckled in for the ride. It's perhaps a modest mission, disentangling ourselves from this journey of Humbert's design, but one which hopefully engenders a practicable type of morality, one which could rewire our understanding of the difference between Dolores and Lolita, between the world's unnumbered Doloreses and the tremendousness of Lolita. And so the "beauty" in question may become, for the first time, Dolores, not delicate but incredible, freed from the haze by readers' freshened sight. It is no one's task but ours to undertake the recovery, recognition, and restoration of a most pervasively and persuasively misunderstood character, one Dolores Haze.

\section{Works Cited}

"About the CDC-Kaiser ACE Study." Centers for Disease Control and Prevention, www.cdc.gov/violenceprevention/acestudy/about.html. Accessed 12 Jan. 2017.

Foucault, Michel. "Sexual Morality and the Law." Politics, Philosophy, Culture: Interviews and Other Writings 1977-1984. Edited by Lawrence D.

Kritzman, translated by Alan Sheridan, Routledge, 1988, pp. 271-285. Lana Del Rey. "Lolita." Born to Die, Interscope, Polydor, and Stranger, 2012. "lolita." Urban Dictionary, 7 Mar. 2004, www.urbandictionary.com/term=lolita. 
Accessed 11 Jan. 2017.

"Lolita (term).” Wikipedia, en.wikipedia.org/wiki/Lolita_(term). Accessed 11 Jan. 2017.

Mann, Sally. "Sally Mann's Exposure." The New York Times Magazine, 16 Apr. 2015, www.nytimes.com/2015/04/19/magazine/the-cost-of-sally-mannsexposure.html?_r=0. Accessed 9 Jan. 2017.

Nabokov, Vladimir. Lolita. 1955. Vintage International, 1997.

Stevens, Jane Ellen. "Got Your ACE Score?" ACESTooHigh. ACEs Connection Network, acestoohigh.com/got-your-ace-score/. Accessed 12 Jan. 2017.

Yuhas, Alan. "Woman who accused Donald Trump of raping her at 13 drops lawsuit." The Guardian, www.theguardian.com/usnews/2016/nov/04/donald-trump-teenage-rape accusations-lawsuit-dropped. Accessed 12 Jan. 2017. 